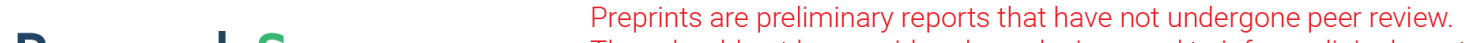 They should not be considered conclusive, used to inform clinical practice, or referenced by the media as validated information. \\ Evaluating physicians' perspective on the efficiency and effectiveness of the electronic prescribing system
}

\section{Reza Khajouei}

Kerman University of Medical Sciences

\section{Reza Abbasi}

Kashan University of Medical Sciences

Ahmad Raeesi ( $\sim$ ah.raesse@gmail.com )

Kerman University of Medical Sciences https://orcid.org/0000-0001-5002-3735

\section{Research article}

Keywords: Evaluation; Electronic Prescription; Electronic Prescribing System; Efficiency; Effectiveness

Posted Date: September 16th, 2019

DOI: https://doi.org/10.21203/rs.2.14453/v1

License: (a) (i) This work is licensed under a Creative Commons Attribution 4.0 International License. Read Full License

Version of Record: A version of this preprint was published at International Journal of Technology Assessment in Health Care on January 1st, 2021. See the published version at https://doi.org/10.1017/S0266462321000052. 


\section{Abstract}

Background The implementation of the electronic prescribing system follows certain objectives and the users' perspectives can contribute to understanding the efficiency and effectiveness of this system. The aim of this study was to evaluate physicians' perspective on the efficiency and effectiveness of the electronic prescribing system. Methods This study was conducted on all physicians using the electronic prescribing system in clinics and hospitals affiliated with the treatment deputy of the Social Security Organization in Sistan and Baluchistan province in Iran. Data were collected using a questionnaire with a reliability of $a=94 \%$ that was developed and validated for this study.Results The mean and standard deviation of the efficiency and effectiveness of the electronic prescribing system were $3.68 \pm 0.67$ and $3.84 \pm 0.65$, respectively. Patient safety had the highest mean score among all the dimensions $(4.0 \pm 0.64)$. Most participants ( $n=55,79 \%)$ considered the efficiency and effectiveness of this system high. More than $90 \%$ of the physicians $(n=63)$ believed that the electronic prescribing system enables a better medication prescription by providing alerts and access to patients' medication history.Conclusion The findings showed that most physicians believed that the electronic prescribing system of Iran's SSO has high efficiency and effectiveness. In particular, using this system improves patient safety and reduces costs.

\section{Background}

One of the systems currently used in medical centers is the electronic prescribing system. The electronic prescribing system uses computerized communication networks to store and transfer physician orders to the pharmacy at the point of care [1, 2]. Previous studies [2-9] have shown that using the electronic prescribing system enhances the efficiency of care providers, improves patient safety, reduces medical costs, increases the effectiveness of services provided, enables access to the patient's medication history and the monitoring of medication interactions, improves medical outcomes and reduces health care expenses.

In the southeast of Iran, due to the small number of physicians in proportion to the population, the number of visits to hospitals and clinics affiliated to the Social Security Organization (SSO) is high, and the time spent by the physician on each patient is therefore limited. According to the results obtained in some studies [10-12], electronic prescriptions take more time to write compared to paper prescriptions. Also, about half of a physician's time is spent on recording data in this method [13] and a large number of errors can occur in outpatient care [12]; however, previous studies have shown that these systems improve patient safety and reduce costs [8].

Efficiency means the expenditure of a certain amount of effort and resources to fully and properly achieve a goal and includes items such as time, costs and ease of performing tasks, etc. [14, 15]. Effectiveness means the full and proper achievement of a goal by the user and includes items such as patient safety, the system's influence on the quality of the provided services, etc. $[14,15]$. Considering that effectiveness can be used for measuring output while efficiency can be used to assess the resources needed to achieve these goals [14], the system's status can therefore be measured by the concurrent evaluation of efficiency 
and effectiveness. Without considering users' perspective and their satisfaction, the system will be abandoned. Accordingly, due to the high costs of developing system, significant financial resources will be required to buying and implement an information system. Thus, it is necessary to evaluate their perspective and satisfaction $[16,17]$. The physicians are the main users of electronic prescribing system.

To our knowledge, no study has been carried out concurrently evaluated the efficiency and effectiveness of the electronic prescribing system from the perspective of physicians despite the extensive use of this systems. Efficiency and effectiveness have been evaluated in few studies as the secondary objective [1820]. To achieve the goals of the successful implementation of the electronic prescribing system, the perspective of physicians can be useful in understanding the efficiency and effectiveness of the system. The aim of this study was to evaluate physicians' perspective on the efficiency and effectiveness of the electronic prescribing system.

\section{Methods}

The electronic prescribing system of the Social Security Organization (SSO)

The electronic prescribing system of SSO's medical centers and hospitals is the most extensive and the only electronic prescribing system implemented countrywide in Iran. This system is used in all medical centers affiliated to SSO, including 70 hospitals and 279 general and specialized clinics throughout the country [21].

The electronic prescribing system implemented in SSO health centers and hospitals works as part of the hospital information system in hospitals and as a separate system in clinics for the registration of medications and para-clinical procedures by physicians and is only available to physicians within these centers. Figure 1 illustrates the professional process of using the electronic prescribing system. In this system, medications can be selected and registered by the physician through both a search and from the list of medications registered as a package (Figure 2). Figure 3 illustrates the medications registered as a package in this system. The medication package is a list of medications that has been arranged first by medication type and then alphabetically and can be selected from an approved box.

This system allows the physician to select the intended medications and then register their order, method of administration and dosage. Medications are then automatically registered in the patient's medication history. Para-clinical measures, including tests, imaging and other procedures, can also be registered. In addition to the registration of medications and procedures, the patient's vital signs, main complaint and current illness, disease history, physical examination results, diagnosis and diagnosis explanation and treatment plan can also be registered in this system. The system warns physicians of any medication interactions or if a certain medication has already been prescribed to the patient by other physicians at a recent time. At the present time, this system only registers the medications available in the relevant health center and other medications not available in the same center are registered as paper prescriptions. 
This descriptive-analytical study was conducted in 2018 on all the physicians using the electronic prescribing system of the SSO in Sistan and Baluchistan Province. Sistan and Baluchistan Province is one of the southeastern provinces of Iran, and its provincial SSO has five general and specialized clinics and two hospitals. This study was conducted a year after the implementation of the electronic prescribing system in this province.

\section{Data collection}

Data were collected using a self-administered questionnaire based on the review of relevant scientific literature. The validity of this questionnaire was confirmed by two medical informatics experts and two health information management experts, and its reliability was measured through a study of 20 of the participants and its Cronbach's alpha was reported as $a=94 \%$.

\section{The questionnaire consisted of three sections:}

1) Six items related to demographic data and clinical experience, computer skills, mean number of hours of computer use per shift and site of using the electronic prescribing system by the participant.

2) Questions related to physicians' perspectives on the efficiency (19 questions) and effectiveness (13 questions) of the electronic prescribing system. The efficiency was in three dimensions, including time (7 questions), costs (5 questions) and other efficiency-related questions (7 questions). The effectiveness was in two dimensions, including patient safety ( 6 questions) and other effectiveness-related items (7 questions). The items were answered based on a five-point Likert scale (including 'totally disagree', 'disagree', 'ineffective', 'agree' and 'totally agree').

3) Open-ended questions related to the most positive and negative aspects of the electronic prescribing system.

Data were collected by the researcher through a visit to the physicians' workplace while using the electronic prescribing system and asking them to complete the questionnaire. Before completing the questionnaire, the participants were briefed on the study and how to complete the questionnaire, and informed verbal consent was obtained from them and completing the questionnaire indicated the participant's consent.

\section{Data analysis}

Data were analyzed using SPSS-18. Descriptive statistics were used to calculate frequency and percentage of the responses. the 'totally agree' and 'agree' options were reported together and the 'disagree' and 'totally disagree' options also reported together. For the analytical statistics, each option on the Likert scale was given a score from one ('totally disagree') to five ('totally agree'), and their mean values were taken as the efficiency and effectiveness scores. The mean value of 3 was considered the 
cut-off point for the efficiency and effectiveness scores, and scores higher than 3 were taken to indicate a good efficiency and effectiveness [22].

The relationship between efficiency and effectiveness was then assessed by the Chi-square test. Normality was assessed using the Kolmogorov-Smirnov test. Given the normal distribution of the data, Pearson's analytical test was used to assess the relationship of age and work experience with efficiency and effectiveness, the relationship of the efficiency dimensions with the effectiveness dimensions, and also the relationship of efficiency with effectiveness. The analytical independent t-test was used to assess the relationship of gender, the site of using the electronic prescribing system and specialization with efficiency and effectiveness. The relationship of computer skills with efficiency and effectiveness was also assessed using the ANOVA.

\section{Results}

Of the 82 participants in the study, 69 (84\%) responded to the questionnaire. Demographic information of the participants is shown in The mean and standard deviation of age and work experience of these participants were $42 \pm 10$ and $12 \pm 8$ years, respectively. Demographic information of participants is shown in Table 1. In total, $56 \%(n=39)$ of the participants were male. The majority of the physicians $(73 \%)$ had a moderate level of computer skills.

The mean and standard deviation of the scores of the efficiency and effectiveness of the electronic prescribing system were $3.68 \pm 0.67$ and $3.84 \pm 0.65$ out of five, respectively. Figure 4 illustrates the mean scores of the different dimensions of efficiency and effectiveness. Among the effectiveness dimensions, 'patient safety' had the highest mean score $(4.0 \pm 0.64)$ and the 'other effectiveness-related items' the lowest mean score $(3.68 \pm 0.73)$. Among the efficiency dimensions, the highest mean score pertained to 'costs' $(3.79 \pm 0.66)$ and the lowest to the 'other efficiency-related items' (3.6 \pm 0.70$)$.

The effect of the electronic prescribing system on efficiency based on the physicians' perspective is shown in Table 2. In the dimension of time related to the efficiency of the electronic prescribing system, the physicians' highest agreement with the electronic prescribing system pertained to the 'correction of mistakes in the shortest time while using the system' and 'saving the patients' time for receiving their medications due to the prescription being based on the pharmacy's availability list' with more than $80 \%$ $(n=56)$. The lowest agreement pertained to 'allocating more time to the patients' with $52 \%(n=36)$. In the dimension of costs, $81 \%(n=56)$ of the physicians believed that the greatest savings were due to the registration of the prescribed medications in the electronic prescribing system and the lowest agreement was obtained for 'the reduced patients' costs' with $52 \%(n=36)$. In the dimension of 'other efficiencyrelated items', the greatest agreement among the physicians pertained to the 'fewer prescription issues such as illegible handwriting' with $81 \%(n=61)$; also, $42 \%(n=29)$ of the physicians believed that the electronic prescribing system has no effect on the patients' visits to health centers.

Table 3 shows the effect of the electronic prescribing system on effectiveness based on the physicians' perspective. In the dimension of 'patient safety', the physicians' highest agreement with the electronic 
prescribing system (91\%; $n=63)$ pertained to 'better medication prescription by providing system's alerts and access to patients' medication history' and the least agreement pertained to 'improvement in medication prescription in accordance with clinical guidelines' $(68 \% ; n=47)$. In the dimension of 'other effectiveness-related items', the highest agreement among the physicians pertained to the 'registration of medications during the patient's visits' with $82 \%(n=57)$ and the lowest to the 'registration of all the intended medications' with $45 \%(n=31)$.

The results of the analytical statistics showed that the mean scores of efficiency and effectiveness had no significant relationship with gender, age, work experience, specialization, the site of using the system or computer skills $(P>0.005)$; however, there were significant positive relationships $(r>+0.6 ; P<0.0001)$ between the mean scores of efficiency and effectiveness and also between all the dimensions of efficiency (time, costs and other efficiency-related items) and effectiveness (patient safety and other effectiveness-related items).

Table 4 shows the relationship between the efficiency and effectiveness of the electronic prescribing system based on the results of the Chi-square test. Most of the participants $(80 \%, n=55)$ considered the efficiency and effectiveness of this system to be high and only a few $(6 \%, n=4)$ regarded the system's efficiency and effectiveness as low.

In response to the two open-ended questions, 20 participants reported positive aspects for the system and 24 participants reported negative aspects, as shown in Table 5."Registration of the patient's medication history" ( $n=14)$, and "Duplicate registration of prescriptions due to the incompatibility of the electronic prescribing system with other systems across the city" $(n=11)$ were the most important positive and negative aspects of electronic prescribing system, respectively.

\section{Discussion}

Core-summary findings

The majority of physicians believed the electronic prescribing system of the SSO has a high efficiency and effectiveness. The most of physicians agreed that the following items increased the efficiency and effectiveness of the electronic prescribing system: Enhanced patient safety, reduced medical errors, better medication prescription by providing alerts and access to patients' medication history, the registration of medications and the correction of mistakes in the shortest time and during the patient's visit, savings in the organization's resources through medication registration, savings in the patients' time for receiving their medications due to prescriptions being based on pharmacies' availability and fewer prescription issues such as illegible handwriting.

Physicians believed that one of the issues that reduces the efficiency and effectiveness of the electronic prescribing system is the registration of all the medications intended by the physician for the patient in the electronic prescribing system, since only medications available in the affiliated medical centers are 
registered through this system and any medications available outside the center are registered on paper, which leads to duplications in the case of referral to other centers.

\section{Comparisons with existing literature}

Like to this study, the results of previous studies demonstrated that the electronics prescription system can enhanced patient safety and reduced medical errors $[4,8,9,23]$. The present findings confirm the results obtained in a study conducted by Lapane et al. [4] to assess users' perception of the efficiency and inefficiency of the electronic prescribing system, which showed that most participants considered the system highly efficient.

Based on the results of this study, more than half of the physicians believed that using this system leads to reduced costs, and number of prescriptions. Similarly, The results of two studies $[24,25]$ showed that using the electronic prescribing system and electronic medication exchange will reduce costs. The results obtained in McMullin et al. study [26] also showed that implementing the electronic prescribing system leads to fewer prescriptions of expensive medications.

In this study, a small number of the participants argued that using the electronic prescribing system increases physicians' interaction with the computer and reduces their interaction with the patients and that physicians spend a long time entering the medication data into the electronic prescribing system and will therefore have less time for a careful examination and eye contact with the patient. This finding concurs with the results obtained by Devine et al. [10] and Hollingworth et al. [11].

Given that some of the problems of this system are caused by its incompatibility with the other systems, the infrastructures needed for the system's compatibility with other systems are recommended to be further considered by policy-makers. Some of the problems of this system have to do with its usability. Future studies are recommended to employ usability methods to assess the efficiency and effectiveness of the system though measuring the time and resources it uses up.

\section{Limitations}

This study had two limitations. First, since it was conducted in only one of the provinces of Iran, and also due to the small statistical population in proportion to the total population of the users of the electronic prescribing system across the country, the data obtained should be generalized with caution; however, since the structure of human resources' distribution is the same in most health centers of the SSO, conducting this study in other centers seems to not produce different results. Second limitation is that physicians' perspective were used in this study to assess the efficiency and effectiveness of the electronic prescribing system and the evaluation of users' perspectives may not be as accurate as the employment of other methods such as timing, which is used to estimate the amount of time spent working with the system to perform a given task, etc. Future studies can use more objective techniques to measure these two components. 


\section{Conclusions}

The result of this study shows the electronic prescribing system improves the efficiency and effectiveness of prescription writing by physicians. In particular, using this system increases patient safety and reduces costs. There were certain concerns involved in the use of this system, including physicians' greater interaction with the computer rather than the patients and increased duplicate medication registrations. Given that some of the problems of this system were associated with its incompatibility with other systems and also its usability, the programmers and developers of electronic prescribing systems are recommended to further consider the compatibility and usability of these systems and seek to upgrade, design and redesign their electronic prescribing systems to increase their efficiency and effectiveness.

The results of this study provided an insight into the problems and benefits of efficiency and effectiveness of electronic prescribing system. Electronic prescribing system are relatively new or in the early stages of their advancement in some developing countries and many of the efficiency and effectiveness problems of this system may have been resolved in developed countries. Thus, developing countries that are recently involved in the designing and implementing of electronic prescribing system encounter same problems. So the results of this study may be helpful for health policy makers and system developers of these countries.

\section{Abbreviations}

SSO: Social Security Organization

SPSS: Statistical Package for the Social Sciences

\section{Declarations}

Ethics approval and consent to participate

Verbal consent was obtained from the participants and the procedure was approved by ethics committee of Kerman University of Medical Sciences (approval number: IR.KMU.REC.1397.262).

Consent for publication

All of Authors consented for publication.

\section{Availability of data and material}

Not applicable.

Competing interests

The authors declare no conflict of interest. 
Funding

This research did not receive any specific grant from funding agencies in the public, commercial, or notfor-profit sectors.

Authors' contributions

RA, RK, and AR designed the study. RK supervised the project. AR collected data and RA analyzed and interpreted the data. All authors discussed the results and reviewed and approved the final manuscript. AR and RK wrote the final manuscript.

Acknowledgements

The authors wish to express their gratitude to all the participating physicians for completing the questionnaire and also the treatment director of the SSO of Sistan and Baluchistan Province for giving their permission to conduct the study.

\section{References}

1. Electronic Prescribing - MeSH - NCBI. https://www.ncbi.nlm.nih.gov/mesh/68055695. Accessed 22 May 2018.

2. S Palappallil D, Pinheiro C. Perceptions of Prescribers towards Electronic Prescription: A PreImplementation Evaluation. Journal of Young Pharmacists. 2018;10:313-7.

3. Dhavle AA, Rupp MT. Towards Creating the Perfect Electronic Prescription. Journal of the American Medical Informatics Association. 2014;22:e7-12.

4. Lapane KL, Rosen RK, Dubé C. Perceptions of e-Prescribing Efficiencies and Inefficiencies in Ambulatory Care. International journal of medical informatics. 2011;80:39-46.

5. Kruse CS, Beane A. Health Information Technology Continues to Show Positive Effect on Medical Outcomes: Systematic Review. Journal of Medical Internet Research. 2018;20:e41.

6. Warholak TL, Rupp MT. Analysis of Community Chain Pharmacists' Interventions on Electronic Prescriptions. Journal of the American Pharmacists Association. 2009;49:59-64.

7. Her QL, Amato MG, Seger DL, Beeler PE, Slight SP, Dalleur O, et al. The Frequency of Inappropriate Nonformulary Medication Alert Overrides in the Inpatient Setting. Journal of the American Medical Informatics Association. 2016;23:924-33.

8. Porterfield A, Engelbert K, Coustasse A. Electronic Prescribing: Improving the Efficiency and Accuracy of Prescribing in the Ambulatory Care Setting. Perspectives in health information management. 2014;11 Spring:1g.

9. Dreischulte T, Donnan P, Grant A, Hapca A, McCowan C, Guthrie B. Safer Prescribing - A Trial of Education, Informatics, and Financial Incentives. New England Journal of Medicine. 2016;374:105364. 
10. Devine EB, Hollingworth W, Hansen RN, Lawless NM, Wilson-Norton JL, Martin DP, et al. Electronic Prescribing at the Point of Care: A Time-Motion Study in the Primary Care Setting. Health Services Research. 2010;45:152-71.

11. Hollingworth W, Devine EB, Hansen RN, Lawless NM, Comstock BA, Wilson-Norton JL, et al. The Impact of e-Prescribing on Prescriber and Staff Time in Ambulatory Care Clinics: A Time-Motion Study. Journal of the American Medical Informatics Association. 2007;14:722-30.

12. Lim WY, HSS AS, Ng LM, John Jasudass SR, Sararaks S, Vengadasalam $P$, et al. The Impact of a Prescription Review and Rrescriber Feedback System on Prescribing Practices in Primary Care Clinics: a Cluster Randomised Trial. BMC Family Practice. 2018;19:120.

13. Sinsky C, Colligan L, Li L, Prgomet M, Reynolds S, Goeders L, et al. Allocation of Physician Time in Ambulatory Practice: A Time and Motion Study in 4 Specialties. Annals of Internal Medicine. 2016;165:753.

14. Iso. 9241-11. Ergonomic Requirements for Office Work with Visual Display Terminals (VDTs): Part 11: Guidance on Usability. The international organization for standardization. 1998;45:9.

15. Georgsson M, Staggers N. Quantifying Usability: An Evaluation of a Diabetes mHealth System on Effectiveness, Efficiency, and Satisfaction Metrics with Associated User Characteristics. Journal of the American Medical Informatics Association. 2016;23:5-11.

16. Khajouei R, Abbasi R. Evaluating nurses' satisfaction with two nursing information systems. CIN Computers Informatics Nursing. 2017;35:307-14.

17. Khajouei R, Peek N, Wierenga PC, Kersten MJ, Jaspers MWM. Effect of predefined order sets and usability problems on efficiency of computerized medication ordering. International Journal of Medical Informatics. 2010;79:690-8.

18. Kannry J. Effect of E-Prescribing Systems on Patient Safety. Mount Sinai Journal of Medicine: A Journal of Translational and Personalized Medicine. 2011;78:827-33.

19. Russ AL, Chen S, Melton BL, Johnson EG, Spina JR, Weiner M, et al. A Novel Design for Drug-Drug Interaction Alerts Improves Prescribing Efficiency. Joint Commission Journal on Quality and Patient Safety. 2015;41:396-405.

20. Kaushal R, Barrón Y, Abramson EL. The comparative effectiveness of 2 electronic prescribing systems. American Journal of Managed Care. 2011;17 SPEC. ISSUE:88-94.

21. Statistics of the Health centers of Social Security Organization in Iran. https://www.tamin.ir/News/Item/33085/73/33085.html. Accessed 31 Aug 2018.

22. Eslami Jahromi M, Ahmadian L. Evaluating Satisfaction of Patients with Stutter Regarding the TeleSpeech Therapy Method and Infrastructure. International Journal of Medical Informatics. 2018;115 February:128-33.

23. Kaushal R, Kern LM, Barrón Y, Quaresimo J, Abramson EL. Electronic Prescribing Improves Medication Safety in Community-Based Office Practices. Journal of General Internal Medicine. 2010;25:530-6. 
24. Weingart SN. An Empirical Model to Estimate the Potential Impact of Medication Safety Alerts on Patient Safety, Health Care Utilization, and Cost in Ambulatory Care. Archives of Internal Medicine. 2009;169:1465.

25. Stenner SP, Chakravarthy R, Johnson KB, Miller WL, Olson J, Wickizer M, et al. ePrescribing: Reducing Costs through In-Class Therapeutic Interchange. Applied Clinical Informatics. 2016;7:1168-81.

26. McMullin ST, Lonergan TP, Rynearson CS. Twelve-Month Drug Cost Savings Related to Use of an Electronic Prescribing System With Integrated Decision Support in Primary Care. Journal of Managed Care Pharmacy. 2005;11:322-32.

\section{Tables}

Table 1: Demographic information of the participants

\begin{tabular}{|l|l|c|}
\hline \multicolumn{2}{|l|}{ Demographic information } & Frequency (Frequency Percentage) \\
\hline \multirow{3}{*}{ Gender } & Male & $39(56 \%)$ \\
\cline { 2 - 3 } & Female & $30(44 \%)$ \\
\hline \multirow{3}{*}{ Site of use } & General & $44(64 \%)$ \\
\cline { 2 - 3 } & Specialist & $25(36 \%)$ \\
\hline \multirow{3}{*}{ Computer skills } & Hospital & $45(65 \%)$ \\
\cline { 2 - 3 } & Clinic & $24(35 \%)$ \\
\cline { 2 - 3 } & Intermediate & $10(15 \%)$ \\
\cline { 2 - 3 } & Advanced & $49(73 \%)$ \\
\hline
\end{tabular}

Table 2: The frequency and frequency percentage of the items on the effect of the electronic prescribing system on efficiency 


\begin{tabular}{|c|c|c|c|c|}
\hline \multirow[t]{2}{*}{ Row } & \multirow[t]{2}{*}{ Item } & Disagree & Ineffective & Agree \\
\hline & & $\begin{array}{l}\text { Number } \\
(\%)\end{array}$ & $\begin{array}{l}\text { Number } \\
\text { (\%) }\end{array}$ & $\begin{array}{l}\text { Number } \\
\text { (\%) }\end{array}$ \\
\hline \multicolumn{5}{|c|}{ A) Dimension of Time } \\
\hline 1 & Allocation of more time to the patients & $\begin{array}{l}19 \\
(27.5 \%)\end{array}$ & $\begin{array}{l}14 \\
(20.3 \%)\end{array}$ & $\begin{array}{l}36 \\
(52.1 \%)\end{array}$ \\
\hline 2 & Reduced waiting time for the patients & $\begin{array}{l}16 \\
(23.2 \%)\end{array}$ & $\begin{array}{l}12 \\
(17.4 \%)\end{array}$ & $\begin{array}{l}40 \\
(58 \%)\end{array}$ \\
\hline 3 & $\begin{array}{l}\text { Spending less time on medication prescriptions compared to the } \\
\text { traditional method }\end{array}$ & $\begin{array}{l}12 \\
(17.3 \%)\end{array}$ & $\begin{array}{l}11 \\
(15.9 \%)\end{array}$ & $\begin{array}{l}46 \\
(66.7 \%)\end{array}$ \\
\hline 4 & $\begin{array}{l}\text { Correction of mistakes in the shortest time while using the } \\
\text { electronic prescribing system }\end{array}$ & $6(8.6 \%)$ & $6(8.7 \%)$ & $\begin{array}{l}57 \\
(82.6 \%)\end{array}$ \\
\hline 5 & $\begin{array}{l}\text { Saving the patients' time for receiving medications due to the } \\
\text { prescription being based on availabilities at the pharmacy }\end{array}$ & $3(4.3 \%)$ & $\begin{array}{l}10 \\
(14.5 \%)\end{array}$ & $\begin{array}{l}56 \\
(81.1 \%)\end{array}$ \\
\hline 6 & Saving the physician's time & $\begin{array}{l}16 \\
(23.2 \%)\end{array}$ & $\begin{array}{l}14 \\
(20.3 \%)\end{array}$ & $\begin{array}{l}39 \\
(56.5 \%)\end{array}$ \\
\hline 7 & Speeding up task performance & $\begin{array}{l}15 \\
(21.7 \%)\end{array}$ & $\begin{array}{l}16 \\
(23.2 \%)\end{array}$ & $\begin{array}{l}38 \\
(55.1 \%)\end{array}$ \\
\hline \multicolumn{5}{|c|}{ B) Dimension of Cost } \\
\hline 8 & General reduction in the treatment costs incurred by patients & $\begin{array}{l}8 \\
(11.6 \%) \\
\end{array}$ & $\begin{array}{l}25 \\
(36.2 \%)\end{array}$ & $\begin{array}{l}36 \\
(52.2 \%)\end{array}$ \\
\hline 9 & Savings in the prescription and use of medications & $\begin{array}{l}7 \\
(10.1 \%) \\
\end{array}$ & $\begin{array}{l}13 \\
(18.8 \%)\end{array}$ & $\begin{array}{l}49 \\
(71 \%) \\
\end{array}$ \\
\hline 10 & Reduced number of prescriptions per patient & $\begin{array}{l}8 \\
(11.5 \%) \\
\end{array}$ & $\begin{array}{l}16 \\
(23.2 \%) \\
\end{array}$ & $\begin{array}{l}45 \\
(65.2 \%)\end{array}$ \\
\hline 11 & $\begin{array}{l}\text { Savings in the organization's resources through medication } \\
\text { registration }\end{array}$ & $4(5.8 \%)$ & $8(11.6 \%)$ & $\begin{array}{l}56 \\
(81.1 \%)\end{array}$ \\
\hline 12 & $\begin{array}{l}\text { Reduced medication costs by choosing medications covered by } \\
\text { insurance }\end{array}$ & $4(5.8 \%)$ & $\begin{array}{l}16 \\
(23.2 \%)\end{array}$ & $\begin{array}{l}49 \\
(71 \%)\end{array}$ \\
\hline \multicolumn{5}{|c|}{ C) Other efficiency-related items } \\
\hline 13 & System's ease of use and not requiring much mental effort & $\begin{array}{l}10 \\
(14.5 \%)\end{array}$ & $\begin{array}{l}17 \\
(24.6 \%)\end{array}$ & $\begin{array}{l}42 \\
(60.9 \%)\end{array}$ \\
\hline 14 & $\begin{array}{l}\text { Reduced number of prescription issues, such as illegible } \\
\text { handwriting }\end{array}$ & $\begin{array}{l}7 \\
(10.1 \%)\end{array}$ & $1(1.4 \%)$ & $\begin{array}{l}61 \\
(88.4 \%)\end{array}$ \\
\hline 15 & Reduced workload for the physicians & $\begin{array}{l}16 \\
(23.2 \%)\end{array}$ & $\begin{array}{l}16 \\
(23.2 \%) \\
\end{array}$ & $\begin{array}{l}37 \\
(53.6 \%) \\
\end{array}$ \\
\hline 16 & Reduced patients' visits to medical centers & $\begin{array}{l}10 \\
(14.4 \%)\end{array}$ & $29(42 \%)$ & $\begin{array}{l}30 \\
(43.4 \%)\end{array}$ \\
\hline 17 & Greater efficiency in performing tasks & $5(7.2 \%)$ & $\begin{array}{l}23 \\
(33.3 \%) \\
\end{array}$ & $\begin{array}{l}41 \\
(59.4 \%) \\
\end{array}$ \\
\hline 18 & Easier task performance for the physicians & $\begin{array}{l}11 \\
(15.9 \%) \\
\end{array}$ & $\begin{array}{l}13 \\
(18.8 \%) \\
\end{array}$ & $\begin{array}{l}45 \\
(65.8 \%)\end{array}$ \\
\hline 19 & Medication and procedure registration in fewer steps & $6(8.7 \%)$ & $\begin{array}{l}14 \\
(20.3 \%) \\
\end{array}$ & $\begin{array}{l}49 \\
(71 \%) \\
\end{array}$ \\
\hline
\end{tabular}


Table 3: The frequency and frequency percentage of the items on the effect of the electronic prescribing system on effectiveness

\begin{tabular}{|c|c|c|c|c|}
\hline \multirow[t]{2}{*}{ Row } & \multirow[t]{2}{*}{ Item } & Disagree & Ineffective & Agree \\
\hline & & $\begin{array}{l}\text { Number } \\
\text { (\%) }\end{array}$ & $\begin{array}{l}\text { Number } \\
\text { (\%) }\end{array}$ & $\begin{array}{l}\text { Number } \\
\text { (\%) }\end{array}$ \\
\hline \multicolumn{5}{|c|}{ A) Dimension of Patient Safety } \\
\hline 1 & Increased patient safety & $2(2.9 \%)$ & $\begin{array}{l}10 \\
(14.5 \%)\end{array}$ & $\begin{array}{l}57 \\
(82.6 \%)\end{array}$ \\
\hline 2 & $\begin{array}{l}\text { Improved medication prescription in accordance with clinical } \\
\text { guidelines (more effective medication prescription) }\end{array}$ & $4(5.8 \%)$ & $\begin{array}{l}18 \\
(26.1 \%)\end{array}$ & $\begin{array}{l}47 \\
(68.1 \%)\end{array}$ \\
\hline 3 & Fewer medical errors & $3(4.3 \%)$ & $\begin{array}{l}11 \\
(15.9 \%)\end{array}$ & $\begin{array}{l}55 \\
(79.7 \%)\end{array}$ \\
\hline 4 & Increased care in providing services & $\begin{array}{l}7 \\
(10.1 \%) \\
\end{array}$ & $20(29 \%)$ & $\begin{array}{l}42 \\
(60.8 \%)\end{array}$ \\
\hline 5 & Better medication prescription by providing system's alerts & $3(4.3 \%)$ & $3(4.3 \%)$ & $\begin{array}{l}63 \\
(93.1 \%) \\
\end{array}$ \\
\hline 6 & $\begin{array}{l}\text { Better medication prescription by access to patients' medication } \\
\text { history }\end{array}$ & $3(4.3 \%)$ & $3(4.3 \%)$ & $\begin{array}{l}63 \\
(93.1 \%) \\
\end{array}$ \\
\hline \multicolumn{5}{|c|}{ B) Other effectiveness-related items } \\
\hline 7 & $\begin{array}{l}\text { Better exchange of information between physicians and the } \\
\text { pharmacy }\end{array}$ & $6(8.7 \%)$ & $\begin{array}{l}12 \\
(17.4 \%) \\
\end{array}$ & $\begin{array}{l}51 \\
(73.9 \%) \\
\end{array}$ \\
\hline 8 & Eliminating physicians' work demands in medication prescription & $\begin{array}{l}8 \\
(11.6 \%)\end{array}$ & $\begin{array}{l}23 \\
(33.3 \%)\end{array}$ & $\begin{array}{l}38 \\
(55 \%) \\
\end{array}$ \\
\hline 9 & Medication registration during the patients' visits & $5(7.2 \%)$ & $7(10.1 \%)$ & $\begin{array}{l}57 \\
(82.6 \%)\end{array}$ \\
\hline 10 & Helpfulness of the system for writing prescriptions & $\begin{array}{l}11 \\
(15.9 \%)\end{array}$ & $\begin{array}{l}24 \\
(34.8 \%)\end{array}$ & $\begin{array}{l}34 \\
(49.2 \%)\end{array}$ \\
\hline 11 & Registration of all the intended medications & $\begin{array}{l}20 \\
(28.9 \%) \\
\end{array}$ & $\begin{array}{l}18 \\
(26.1 \%) \\
\end{array}$ & $\begin{array}{l}31 \\
(44.9 \%) \\
\end{array}$ \\
\hline 12 & $\begin{array}{l}\text { Facilitating a greater control over the prescription of daily } \\
\text { medications }\end{array}$ & $2(2.9 \%)$ & $\begin{array}{l}16 \\
(23.2 \%) \\
\end{array}$ & $\begin{array}{l}51 \\
(73.9 \%) \\
\end{array}$ \\
\hline 13 & $\begin{array}{l}\text { Increased general effectiveness of the physician in prescribing } \\
\text { medications }\end{array}$ & $5(7.2 \%)$ & $\begin{array}{l}16 \\
(23.2 \%)\end{array}$ & $\begin{array}{l}48 \\
(69.6 \%)\end{array}$ \\
\hline
\end{tabular}

Table 4: The relationship between the efficiency and effectiveness of the electronic prescribing system

\begin{tabular}{|c|c|c|c|c|c|}
\hline & \multicolumn{2}{|c|}{ Efficiency } & \multirow[t]{2}{*}{ Total } & \multirow[t]{2}{*}{ P-Value } \\
\hline & & $\begin{array}{l}\text { Low } \\
\text { Number (\%) }\end{array}$ & $\begin{array}{l}\text { High } \\
\text { Number (\%) }\end{array}$ & & \\
\hline \multirow[t]{2}{*}{ Effectiveness } & $\begin{array}{l}\text { Low } \\
\text { Number (\%) }\end{array}$ & $4(5.8 \%)$ & $3(4.3 \%)$ & 7 (10.1\%) & \multirow[t]{3}{*}{0.021} \\
\hline & $\begin{array}{l}\text { High } \\
\text { Number (\%) }\end{array}$ & $7(10.1 \%)$ & $55(79.8 \%)$ & 62 (89.9\%) & \\
\hline \multicolumn{2}{|l|}{ Total } & $11(15.9 \%)$ & $58(84.1 \%)$ & $69(100 \%)$ & \\
\hline
\end{tabular}

Table 5: The positive and negative aspects of using the electronic prescribing system 


\begin{tabular}{|c|c|}
\hline Positive aspects & Negative aspects \\
\hline $\begin{array}{l}\text { Registration of the patient's } \\
\text { medication history }(\mathrm{n}=14 \text { ), } \\
\text { Assessment of medication } \\
\text { interactions ( } \mathrm{n}=5 \text { ), Increased } \\
\text { speed of medication } \\
\text { registration ( } \mathrm{n}=3 \text { ), Reduced } \\
\text { medication errors, Access to } \\
\text { the patient's history if } \\
\text { implemented nationwide, } \\
\text { Medication prescription based } \\
\text { on availability at the pharmacy, } \\
\text { Reduced uncontrolled use of } \\
\text { medications and savings in } \\
\text { medication use ( } \mathrm{n}=2 \text { ), Seeing } \\
\text { the entire list of medications } \\
\text { and their control, Use of less } \\
\text { paper ( } \mathrm{n}=1 \text { ). }\end{array}$ & $\begin{array}{l}\text { Duplicate registration of prescriptions due to the incompatibility of the } \\
\text { electronic prescribing system with other systems across the city }(n=11) \text {, } \\
\text { Greater interaction with the computer rather than the patient }(n=9) \text {, } \\
\text { Ergonomic problems of working with the computer }(n=4) \text {, Sudden } \\
\text { interruptions and disruptions in the system }(n=3) \text {, Limitations in medication } \\
\text { prescription, Non-elimination of paper prescriptions, Lack of access to the } \\
\text { system outside the hospital, Physicians' dependence on the computer, No } \\
\text { access to the patient's photo for identification }(n=1) \text {. }\end{array}$ \\
\hline
\end{tabular}

\section{Figures}

\begin{tabular}{|c|c|c|c|}
\hline $\begin{array}{l}\text { Registration and } \\
\text { confirmation of the } \\
\text { patient's insurance and } \\
\text { demographic details at } \\
\text { the time of admission } \\
\text { and providing the } \\
\text { patient with a } \\
\text { "password" }\end{array}$ & $\begin{array}{l}\text { The patient's visit to the } \\
\text { clinic, physician } \\
\text { clicking on the patient's } \\
\text { name and uploading his } \\
\text { details after entering a } \\
\text { password }\end{array}$ & $\begin{array}{l}\text { Registration of } \\
\text { medications according } \\
\text { to a medication list, } \\
\text { medication interaction } \\
\text { control and ensuring no } \\
\text { duplicate medications, } \\
\text { clicking on the "save" } \\
\text { button and sending to } \\
\text { the pharmacy }\end{array}$ & $\begin{array}{l}\text { The patient visiting the } \\
\text { pharmacy, giving his } \\
\text { password, printing the } \\
\text { use instruction label } \\
\text { and receiving the } \\
\text { medications }\end{array}$ \\
\hline
\end{tabular}

\section{Figure 1}

The process of working with the electronic prescribing system 


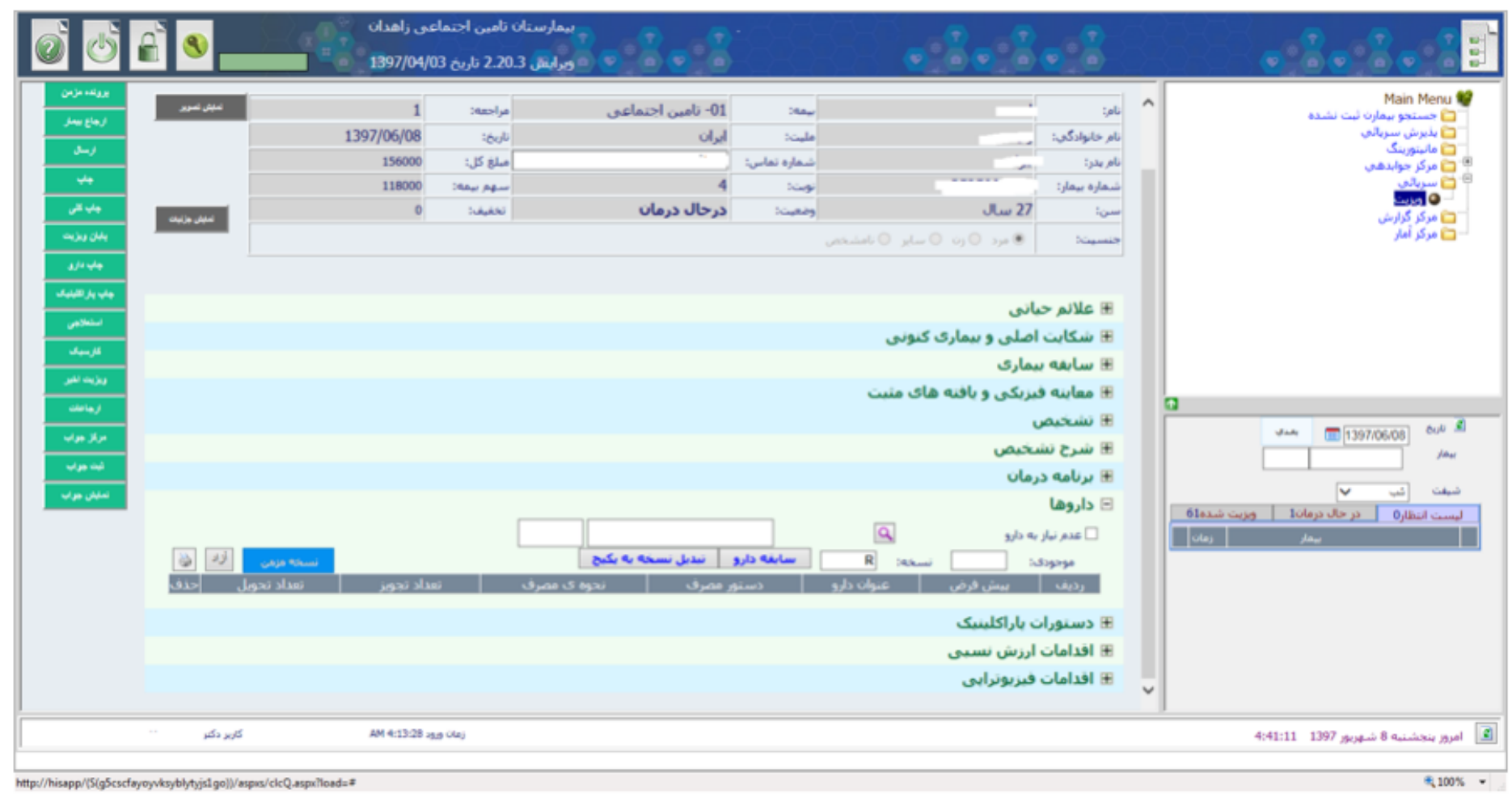

Figure 2

A sample physician's desktop for the registration of medications and procedures (There is no identifiable information in the figure) 


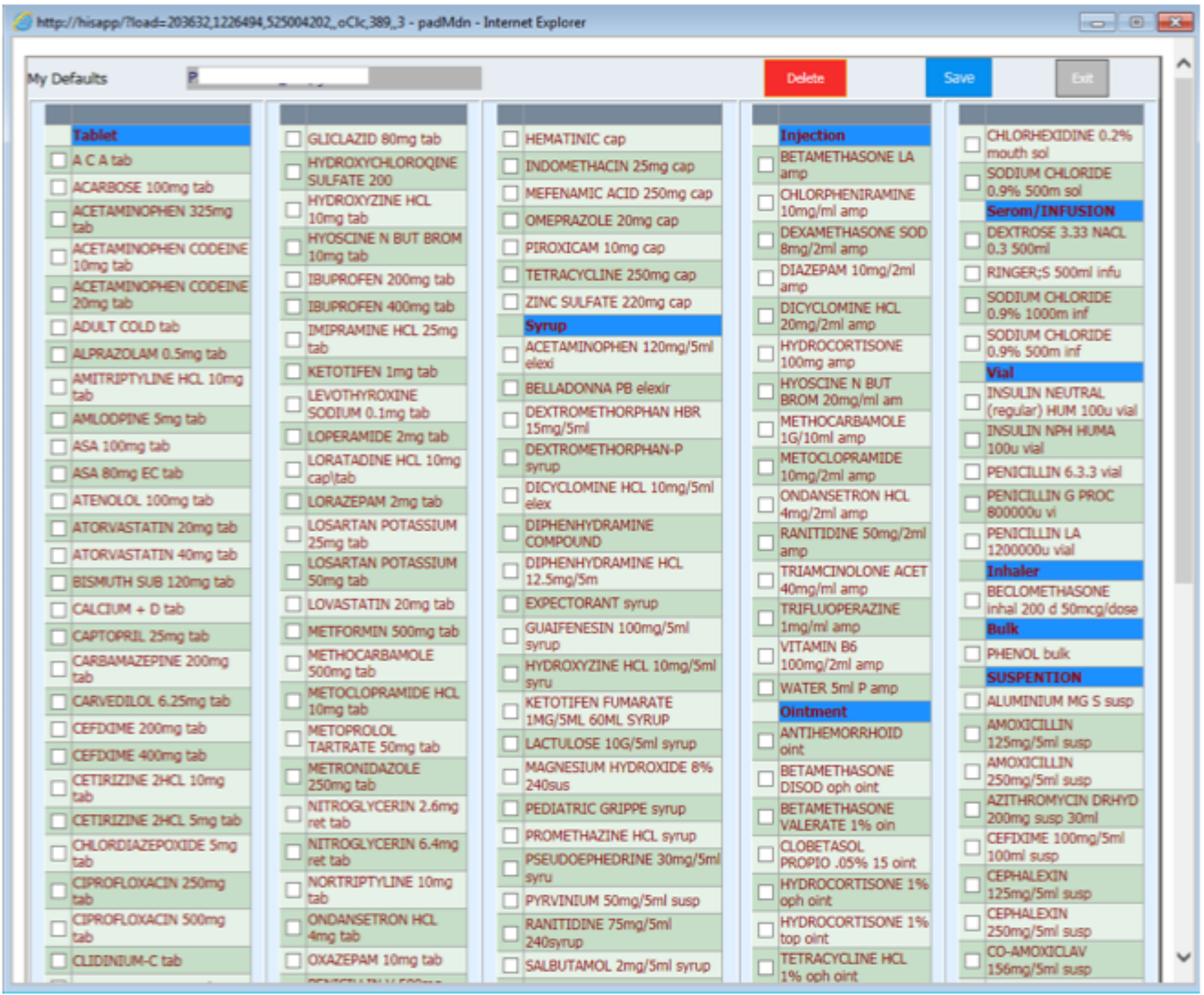

\section{Figure 3}

The page of the medications registered as a package in the electronic prescribing system 


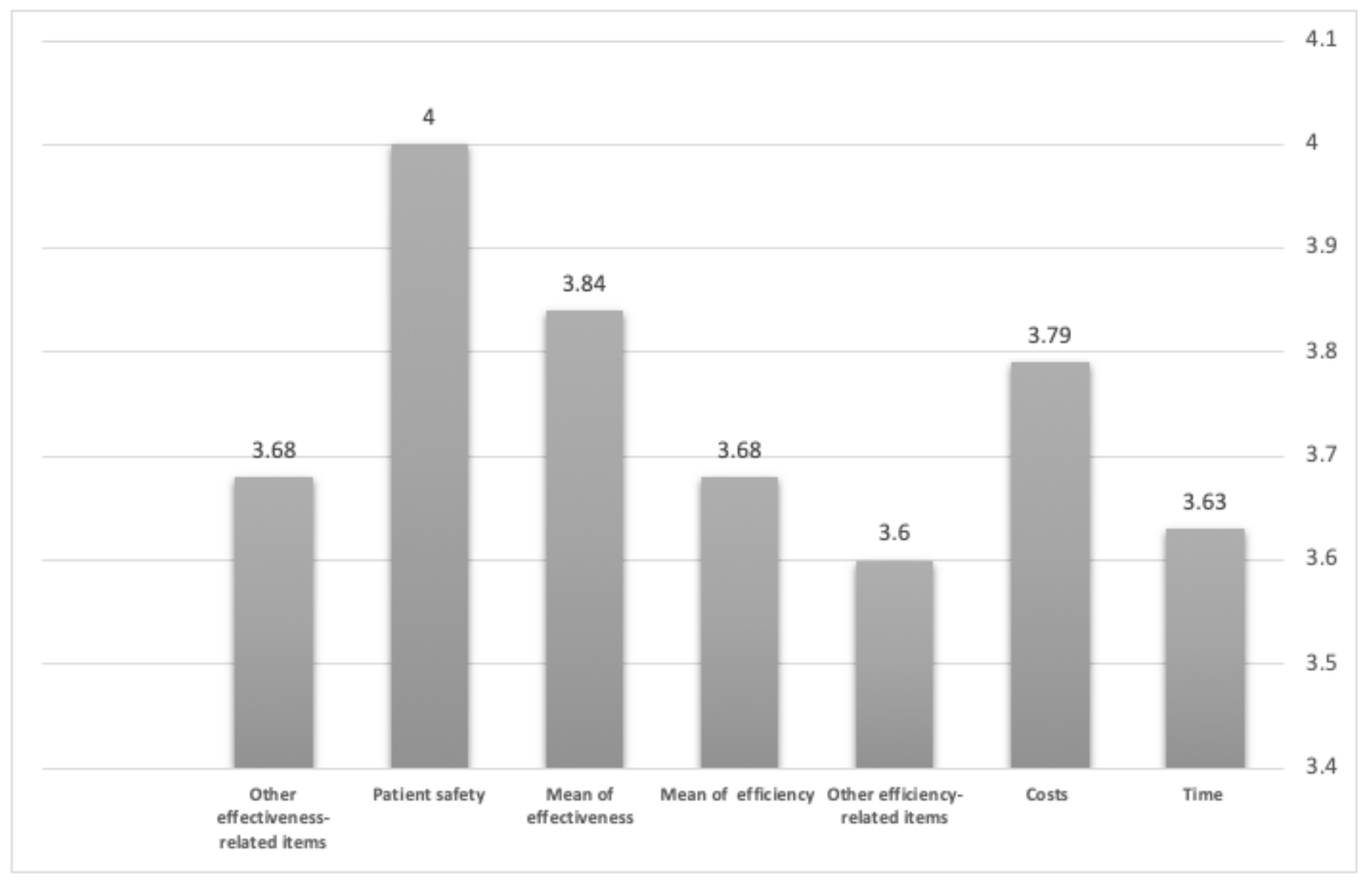

\section{Figure 4}

The mean scores of the different dimensions of the efficiency and effectiveness of the electronic prescribing system 